NASA Technical Memorandum 101572

\title{
RESULTS OF A PARAMETRIC AEROELASTIC STABILITY ANALYSIS OF A GENERIC X-WING AIRCRAFT
}

Jessica A. Woods, Michael G. Gilbert, and Terrence A. Weisshaar

\section{APRIL 1989}

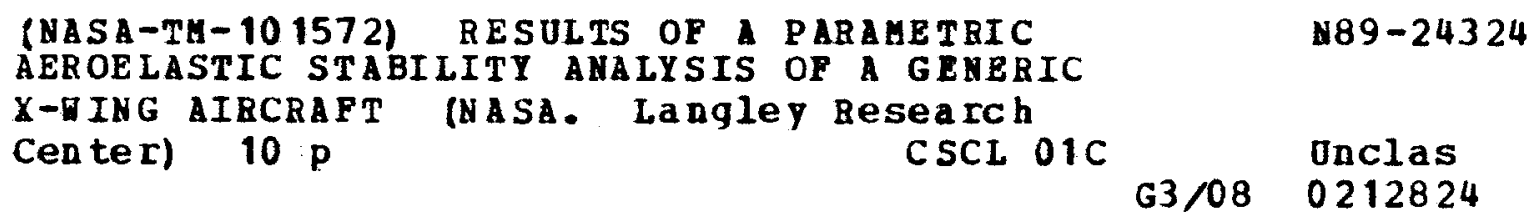

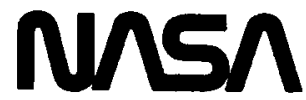

National Aeronautics and

Space Administration

Langley Research Center

Hampton, Virginia 23665-5225 


\author{
Jessica A. Woods * \\ Planning Research Corporation, Hampton, VA. \\ Michael G. Gilbert** \\ NASA Langley Research Center, Hampton, VA. \\ Prot. Terrence A. Weisshaar ${ }^{\dagger}$ \\ Purdue University, W. Lafayette, IN.
}

\begin{abstract}
This paper discusses the trends in longitudinal dynamic aeroelastic stability of a generic $X$-Wing aircraft model with design parameter variations. $\mathrm{X}$-Wing rotor blade sweep angle, ratio of blade mass to total vehicle mass, blade structural stiffness cross-coupling and vehicle center-of-gravity location were parameters considered. The typical instability encountered is body-freedom flutter involving a low frequency interaction of the first elastic mode and the aircraft short period mode. Parametric cases with the lowest static margin consistently demonstrated the highest flutter dynamic pressures. As mass ratio was increased, the flutter boundary decreased. The decrease was emphasized as center-of-gravity location was moved forward. As sweep angle varied, it was observed that the resulting increase in forward-swept blade bending amplitude relative to aft blade bending amplitude in the first elastic mode had a stabilizing effect on the flutter boundary. Finally, small amounts of stiffness crosscoupling in the aft blades increased tlutter dynamic pressure.
\end{abstract}

\section{Introduction}

The $X$-Wing aircralt is a unique vehicle configuration combining the vertical take-off advantages of a helicopter and the high-speed forward tlight capability of a fixed wing aircraft. The aircraft concept utilizes a four bladed, bearingless rotor system capable of operation in three thight phases. Vertical take-off and hover with rotating blades comprise the first flight phase. The second phase is a conversion mode in which the blade rotation slows to a stop. In the third phase, the stopped rotor blades act as fixed wings for high speed forward flight [1]. Two of the blades are swept forward and two are swept aft symmetrically. From this configuration, the aircraft has become known as the "X-Wing."

In each of these phases of flight, circulation control provides a mechanism for augmenting and controlling lift [2]. Essentially, circulation control is achieved by

\footnotetext{
*Aerospace Engineer, Aerospace Technologies Division. Member AIAA.

**Aerospace Engineer, Aeroservoelasticity Branch, Struc: tural Dynamics Division. Member AlAt

tProfessor, School of Aeronautics and Astronautics Engineering. Associate Fellow ALAA.
}

blowing a sheet of air through spanwise slots over the trailing edges of Coanda airtoils. Because these quasielliptical airfoils have rounded trailing edges, the flow remains attached and the airfoils' stagnation point is relocated. Thus, lift and stability can be modulated by controlling the velocity and spanwise distribution of blowing.

It has been demonstrated in the past that fixed-wing aircraft with forward-swept wings exhibit substantial coupling between elastic and rigid-body vibration modes. This symmetric, low frequency flutter condition is commonly referred to as 'body-freedom' flutter and is a coupling of wing bending and rigid-body pitch and plunge motions [3]. Because of the similarities between this configuration and the $\mathrm{X}$-Wing in a fixed rotor mode, it is likely that such an instability will be characteristic of the vehicle.

Several studies have focused on the aeroelastic stability of this unique configuration. For instance, in 1981, Gimmestad [4] conducted a study of an X-Wing configuration which included rigid-body freedoms as well as circulation control blowing along the blades. The results indicate that aft biade motion damps unstable forward blade motion through body freedoms until high velocities when the vehicle loses stability in pitch and a whole vehicle divergence results.

In 1987, Gilbert and Silva [5] showed analytically that with increasing airspeed aeroelastic deformations of an $X$-Wing configuration caused a forward shift in the aircraft aerodynamic center (a.c.) location. The result, again, is a loss of static margin or vehicle divergence. Compared to the previous study, however, the divergence occurred at lower airspeeds which is due to lower blade natural frequencies and higher pitch inertia. It was also concluded that no antisymmetric divergence or flutter modes exist.

More recenLly, Haas [6] has investigated an X-Wing configuration with circulation control blowing but without rigid-body freedoms. At high angles of attack, a single degree of freedom flutter involving first bending elastic mode occurs. The instability is due to the airfoil section's negative lift curve slope at high angles. It is emphasized that the flutter is not dynamic stall, as there is no flow separation. At reduced angles of attack, classical bending-torsion flutter is observed. With no circulation control blowing, the highly rigid vehicle experiences classical bending-torsion flutter and static divergence at very high airspeeds.

The intent of this study is to determine the dynamic aeroelastic behavior of the generic $X$-Wing aircraft 
conilguration with body freedoms. As a basis for the study, a generalized X-Wing aeroelastic model is developed for the vehicle in a stopped rotor mode. Composite-beam finite elements were used to model the $\mathrm{X}$.Wing blade structure and Doublet Lattice lifting surface theory [7] is used to calculate the unsteady aerodynamics. Variations in both structural and aerodynamic parameters are made to determine trends in the tlutter behavior. The analysis uses only symmetric vibration modes and does not include circulation control blowing.

\section{deroelastic Model Development}

\section{Equations of Votion}

The equations of motion for a free-flying aeroelastic vehicle are, in terms of vehicle rigid body and elastic vibration modes [8],

$$
\left.\left[[M] s^{2}+\left[C^{\prime}\right] s+\left[K^{\prime}\right]+\frac{}{q[Q}(s)\right]\right]\{\eta(s)\}=0
$$

where $q$ is the dynamic pressure, $[Q(s)]$ is the matrix of generalized aerodynamic forces, $\{\eta(s)\}$ is the vector of generalized coordinates, and $s$ is the Laplace transform variable. $\left[\mathrm{M}^{\prime}\right],\left[\mathrm{C}^{\prime}\right]$ and $\left[\mathrm{K}^{\prime}\right]$ are the generalized mass, damping and stitiness matrices, respectively.

\section{Strucnural Model}

To model the generic $\mathrm{X}$-Wing configuration, a structural half-model was developed using beam finite elements. The model was general in the sense that parametric variations could easily be made in the sweep angle, mass and stiffness properties. The beam element was incorporated into EAL (Engineering Analysis Language) for free vibration analysis of the model [9].

The finite element used in this study was developed to model beams demonstrating bending-torsion stiffness cross-coupling and is described by elemental mass and stiffness matrices which are fully defined in reference [10]. Both elemental matrices involve a nondimensional parameter, $\Psi$, which describes the stiffness crosscoupling. It is defined by Weisshaar [11] as

$$
\psi= \pm \sqrt{R^{2} / E I \cdot G J}
$$

where EI and GJ are the bending and torsional stiffnesses of the beam, respectively, and $\bar{K}$ denotes stiffness crosscoupling between bending and torsional deformations. Limits on $\psi$ are derived from the energy requirement that a stiffness matrix must be positive semi-detinite

$$
\left[\begin{array}{cc}
E I & \widetilde{K} \\
K & G J
\end{array}\right] \geq 0.0
$$

or equivalendy

$$
\mathrm{EIGJ}-\widetilde{\mathrm{K}}^{2} \geq 0.0
$$

which implies

$$
-1 \leq \psi \leq 1
$$

$d$ positive value of $\psi$ indicates that upward (positive) beam bending induces a leading edge up twist or 'washin'. A negative value implies negative twist with positive beam bending or 'washout'. $\Psi=0$ represents the absence of stiffness cross-coupling. Physically, $\psi$ is determined by the composite ply orientation within a given composite laminate.

The actual $\mathrm{X}$-Wing structural half-model takes advantage of the vehicle's symmetry while in the fixed rotor mode. It consists of two untapered blades, one with forward sweep and one with aft sweep, each modeled by ten finite elements. The specific nodal layout and some parameter definitions are illustrated in Figure 1.

Vehicle center-of-gravity (c.g.) location, also shown in Figure 1, is determined by the two mass components of the $\mathrm{X}$-Wing half-model. One mass component is the set of two blades. The other is an attached mass simulating the fuselage and is positioned at varying locations along the vehicle's longitudinal axis. The element used to link fuselage and blade motion is massless and rigid.

Some typical natural frequencies and modeshapes computed in this study are shown in Figure 2.

\section{Aerodynamic Model}

The X-Wing half-model is further developed by detining aerodynamic lifting surfaces. Combining these planform geometries with the free vibration modeshapes and frequencies, an unsteady aerodynamic analysis can be conducted to determine generalized aerodynamic torces (GAF's) acting on the vehicle at various reduced frequencies.

Two assumptions have been made in the aerodynamic calculations. First, because symmetric structural vibration modeshapes are used for analysis, the aerodynamics are also specified as symmetric about the $x-z$ plane. Second, circulation control blowing has not been included. Although it was shown by Haas [6] that the strength and spanwise distribution of blowing directly affect the static and dynamic aeroelastic vehicle responses, it is assumed in the present study that there is no circulation control along the blades.

Unsteady GAFs in this investigation are computed using the Doublet Lattice Method as available in ISAC (Interaction of Structures, Aerodynamics and Controls) [12]. They are tabulated as functions of Mach number and reduced frequency, $k$, defined as $k=\frac{\omega b}{V}$ where $\omega$ is the oscillation frequency, $b$ is one-half the blade chord length and $V$ is the velocity. GAFs are computed for harmonic motion and are extended to arbitrary motion using a rational function approximation method described below. In these computations, $\mathrm{Mach}=0.3$ and sea level conditions are assumed. A representative Doublet Lattice panel layout is shown in Figure 3. 
The rational function approximation to the tabulated GAFs is made in the form [8]

$$
\begin{aligned}
{[Q(s)]=\left[A_{0}\right]+\left[A_{1}\right]\left(\frac{b s}{V}\right)+} & \\
& {\left[A_{2}\right]\left(\frac{b s}{V}\right)^{2}+\sum_{i=1}^{L} \frac{\left[B_{i}\right]^{s}}{V B}\left(s+\frac{V i}{b}\right) }
\end{aligned}
$$

where $L$ is the number of aerodynamic lags and $\beta_{i}$ are the aerodynamic lag coefficients. $\left[A_{0}\right],\left[A_{1}\right],\left[A_{2}\right]$, and the $\left[B_{i}\right]$ 's are real and are computed using a least squares fit to the tabulated GAFs for the case of harmonic motion, $s=j \omega$. The lags, $\beta_{i}$, are arbitrarily chosen to be within the reduced frequency range under invesugation and provide a good approximation for $s=j \omega$. The approximations are constrained to be an exact fit to the tabulated GAF's at $k=0$ in order to define as accurately as possible forces generated by rigid body modes and the steady state aerodynamics. In this study, there are four aerodynamic lag coefficients, $\beta=0.1,0.15,0.25,0.4$ and ten values of reduced frequency in the range of $k=0.0$ to $\mathrm{k}=1.0$.

\section{State Soace Formulation}

With the aerodynamics in functional form and the structural matrices defined, the equation of motion, Eqn. 1 , can be rewritten in state space form for stability analysis as shown in the Appendix [8].

\section{Aeroelastic Stability Analvses}

\section{Analysis Method}

Having developed a generalized $\mathrm{X}$-Wing model, parametric variations may now be made and the vehicle stability studied. A parametric variation is the changing of some vehicle dimension, stiffness or mass property while fixing the other system parameters to some nominal values. Each specific combination of parametric and nominal values is referred to as a 'configuration'. In this study, center-of-gravity, sweep angle, blade-to-vehicle mass ratio and stiffness cross-coupling are chosen to be the system parameters. The nominal value of each parameter is listed in Table I.
Table I Nominal parameter values

$\begin{array}{lll}\Lambda & 45^{\circ} & \text { sweep angle } \\ \mathrm{m}_{\mathbf{r}} & 0.25 & \begin{array}{l}\text { blade-to-vehicle mass ratio } \\ \psi\end{array} \\ \begin{array}{ll}\text { suffness cross-coupling } \\ \text { in forward aft blades }\end{array} \\ \overline{\mathrm{x}} & -0.0 / 0.0 & \text { center-of-gravity location }\end{array}$

The ISAC stability analysis for each case involves determining the eigenvalues of the associated system matrix [F], Eqn. A-6 in the Appendix, over a range of velocities. A complex eigenvalue or root is stable when the real part is less than zero. A positive real part implies unstable, i.e. positively damped, oscillatory motion of the associated rigid-body or elastic mode. A real root is stable if it is less than zero and unstable if it is greater than zero.

\section{Nominal Configuration}

To illustrate typical trends in X-Wing stability, the root locus of the nominal forward c.g. case $(\bar{x}=-0.15)$ is presented in Figure 4. Velocity variation is in approximately $30 \mathrm{mph}$ intervals between 30 and $600 \mathrm{mph}$. Since only the first two elastic modes and rigid body modes show any tendency towards instability, higher modes have not been shown. First and second elastic mode roots repel one another; the first mode frequency decreasing while the second mode frequency increases. Coupling of the first elastic mode with the vehicle short period mode creates a body-freedom flutter condition.

\section{Mass Ratio Variation}

Mass ratio, $m_{r}$, is defined for the half-model as the ratio of total blade mass over total vehicle mass,

$$
m_{r}=\frac{m_{b}}{m_{b}+m_{f}}
$$

where $m_{f}$ is the attached fuselage mass and $m_{b}$ is the mass of two blades. The nominal value of $m_{r}$ is 0.25 . Pitch inertia as well as total vehicle mass are held constant during $m_{r}$ variations. Configurations are examined at $\mathrm{m}_{\mathrm{r}}=0.15,0.25,0.35,0.45$, and 0.55 , in each case at two forward c.g. locations, $\bar{x}=-0.15$ and $\bar{x}=-0.3$.

Velocity root loci are, for most of the cases, similar to those shown in Figure 4. First and second elastic mode roots move away from one another as velocity increases; interaction between the short period and first elastic roots results in the latter roots moving to the righthalf plane. The exception is for the case with $m_{r}=0.15$ and $\bar{x}=-0.15$. Contrary to the typical trend, as velocity increases, the short period roots are driven to the right-half plane while the tirst elastic mode roots are forced to the 
leit The instability mode, however, is still body-freedom thutter.

Several interesting results were obtained from the stability analysis. These results are summarized in Figure 5 which presents the tlutter dynamic pressure as a function of mass ratio. Figure 5 shows that at $m_{r}=0.15$, flutter boundaries for $\bar{x}=-0.15$ and $\bar{x}=-0.3$ cases intersect. Further investigation shows that these two cases are essentially the same configuration. With small mass ratios, the fuselage is massive enough to create a 'nearclamped' fuselage condition so that c.g. location is no 'longer a factor. Furthermore, since the structural characteristics of the blades are the same for a given $m_{r}$ at any c.g. location, the first two elastic mode natural irequencies are nearly identical.

As mass ratio increases, the effect of c.g. location is to separate the flutter boundaries. Cases with the more forward c.g. locations lead to the lower flutter dynamic pressures. In addition, Figure 5 shows that an overall decrease in Hutter dynamic pressure, $q_{f}$, occurs as mass ratio increases. This happens because blade first mode natural irequencies decrease by as much as $50 \%$ when $\mathrm{m}_{\mathrm{r}}$ is increased from 0.15 to 0.55 , as shown in Figure 6 , allowing short period and tirst elastic modes to interact at increasingly lower dynamic pressures. The decrease occurs because blade mass per unit length, which is inversely proportional to the square of natural frequency, increases with $m_{r}$.

\section{Sweep Angle Variation}

As shown in Figure 1, blade sweep angle is detined as one-half the relative angle between forward-and aft-swept $X-W i n g$ rotor blades. The nominal value is $\Lambda=45^{\circ}$. Configurations examined are $A=15^{\circ}, 30^{\circ}, 45^{\circ}, 60^{\circ}$, and $75^{\circ}$, each with c.g. locations $\bar{x}=-0.15$ and -0.3 .

Velocity root loci for the various sweep configurations are similar to those shown in Figure 4. The first elastic mode and short period mode roots interact to create a body-ireedom flutter condition. However, as $\Lambda$ increases, a transition occurs. The $\Lambda=15^{\circ}$ cases have short period mode roots moving to the right half plane at flutter, whereas, the $\Lambda=45^{\circ}$ cases have first elastic mode roots moving to the right half plane. This transition is shown in Figure 7, a root locus for the configuration described by $\Lambda=30^{\circ}$ and $\bar{x}=-0.3$. There is a velocity at which first elastic mode roots and short period mode roots become indistinguishable. It is unclear which roots pass into the right half plane. A similar transition also occurs in the $\bar{x}=-0.15$ cases but at a swecp angle not investigated $\left(15^{\circ}<\Lambda<30^{\circ}\right)$.

Structural vibration modeshapes for representative cases $\Lambda=15^{\circ}$ and $45^{\circ}$, both with $\bar{x}=-0.15$, are compared in Figure 8 . In the first elastic mode of the $1=45^{\circ}$ case, both blades move together with the aft blade having a larger relative amplitude. As $\Lambda$ decreases below $45^{\circ}$, a "modeswitch" occurs and, in the extreme case of $\Lambda=15^{\circ}$, it is seen that forward and aft blades move opposite to one another although the aft blade still has a larger relative amplitude. Thus, at some transition sweep angle, denoted as $\Lambda_{t r}$, the first elastic mode involves, primarily, bending of the aft blade and no relative forward-blade bending. $\Lambda_{\text {tr }}$ increases with forward motion of the c.g.. For $\bar{x}=-0.15$ cases, $\Lambda_{t r} \approx 30^{\circ}$ while for $\bar{x}=-0.3$ cases, $\Lambda_{t r} \approx 45^{\circ}$.

Results of the dynamic stability analysis are shown in Figure 9. Several interesting observations were made. In both $\bar{x}=-0.15$ and -0.3 cases, minimums in flutter boundaries are present. The sweep angle at which these minimums occur are denoted by $\Lambda \mathrm{m}$. In the $\overrightarrow{\mathrm{x}}=-0.15$ case, $\Lambda_{m}=38^{\circ}$ and in the $\bar{x}=-0.3$ case, $\Lambda_{m}=45^{\circ}$. A qualitative investigation of the static margin variation with $\Lambda$ has shown that these minimums are associated with maximums in static margin [13]. This is consistent with previous results obtained. In the $\mathrm{m}_{\mathrm{r}}$ variations, it was shown that increasing static margin led to decreasing flutter dynamic pressure. In addition, as the c.g. location is moved aft, the maximum static margin occurs at a higher sweep angle and, thus, the stability curve is shifted to the right. The stability boundary minimums are associated, too, with the modeshape transition. For the most unstable case, the first elastic modeshape involves very little or no forward-blade bending amplitude relative to aft-blade bending amplitude. The a.c. is in its most aft position and static margin is maximum or near maximum. As forvard blade bending amplitude increases or decreases with variations in $\Lambda$, the a.c. is shifted forward and the static margin is reduced. Thus, forwardblade loads counteract att-blade loads and tend to stabilize the vehicle.

\section{Aeroelastic Tailoring}

The final objective of this study was to tind a means of delaying or eliminating body-freedom flutter of the $X$ Wing. For this purpose, aeroelastic tailoring through the use of stiffness cross-coupling was investigated. This coupling was incorporated independently into the forwardand aft-swept blades of a nominal parametric configuration and in varying amounts: $\psi=-0.5,-0.25,0.25$, and 0.5 .

Velocity root loci for the tailored $\mathrm{X}$-Wing configurations were found to be very similar to the typical root locus shown earlier in Figure 4. All cases experience body-freedom flutter as a result of short period and first mode interaction.

The vehicle tlutter dynamic pressure as a function of blade stiffness cross-coupling is shown in Figure 10. In this figure, one flutter boundary is associated with cases in which $\Psi$ changes only on the forward blades and remains zero in the aft blades. The other curve represents a boundary for cases with $\psi$ changes in the aft blade while forward-blade cross-coupling is zero. It is seen that stiffness tailoring of the forward-swept blades has a small effect on the flutter stability of the parametric case svaluated. The result is not surprising because the forward-swept blades have a small bending amplitude relative to the aft-blade bending amplitude in the first elastic mode of this configuration. Thus, changes in aerodynamic loading due to coupling-induced washin or 
washout of the forward blades are small when compared to the aft-blade loads.

With negative cross-coupling, 'washout', in the aftswept blades, the natural tendency of the blades to washout during bending is magnified. As a result of the decreased aerodynamic loads, the static margin is decreased. It has been shown previously that a decrease in static margin increases flutter dynamic pressure. The addition of positive cross-coupling, washin, in the aft blades causes the thutter dynamic pressure to decrease below the uncoupled llutter dynamic pressure. The natural tendency - of the blade to washout has been dominated by stiffnessinduced washin. As a result of the increased blade loading, static margin is increased and tlutter dynamic pressure declines.

There exists a point of diminishing retums, where furcher increases $\psi$ lead to decreases in $q_{\mathrm{f}}$. This may be explained by considering the decrease in first mode natural frequencies as the magnitude of $\psi$ increases. The frequencies change slighuly because both the mass matrix elements and the bending stiffness are functions of $\psi$. As the magnitude of $\psi$ increases, variations in the mathematical model increasingly affect the system characteristics. In this case, the lower frequencies allow for intcraction of short period and first clastic mode roots at lower dynamic pressures or $\mathrm{q}_{\mathrm{f}}$.

\section{Pitch Vloment Effects}

An analysis involving vehicle stability as a function of c.g. location yields some interesting insight into vehicle stability trends. The locations considered were $\bar{x}=-0.3,-0.15,-0.075,0.0$, and +0.15 . Figure 11 summarizes the results. The upper curve defines a boundary above which body-freedom flutter occurs. For $\overline{\mathrm{x}}<-0.15$, tlutter dynamic pressure is slightly less than that of the nominal case. It increases dramatically as the c.g. is moved aft. which is effectively decreasing the static margin. The lower curve is a restabilization boundary of the vehicle divergence condition which is consistently observed in the cases where the initial a.c. location is forward of the vehicle c.g..

As illustrated in the root locus of an initially unstable case. Figure 12, the short period mode root lies along the positive real axis and moves outward with increases in velocity. The root eventually reaches a limit and begins to the left along the real axis. Restabilization of the root is followed at higher velocities by the body-freedom flutter condition described previously.

Insight is gained by considering the first elastic modeshape as a function of c.g. location, Figure 13. In the forward c.g. locations, aft-swept blade bending amplitude is much larger than forward blade bending amplitude. At $\vec{x}=0.0$, blades bend together with the same amplitude because the vehicle is longitudinally symmetric. As c.g. is moved aft, forward blade bending becomes the dominant bending amplitude. Herein lies the possibility of vehicle divergence for the statically unstable cases. At low velocities, forward swept blades begin to develop larger airloads due to aeroelastic washin. Because forward blade bending amplitude is significantly larger than aft blade bending amplitude in these cases, there is insulficient nosedown pitch moment generated by the att blades to counteract noseup moments due to the forward blade airloads. Thus, the $\mathrm{X}$-Wing experiences a vehicle divergence instability characterized by an aperiodic upward pitch. As velocity increases, forward-swept blade inertial loads [15] and aft blade airloads increase, theoretically restabilizing the vehicle. One implication of this is that stability augmentation of the divergent motion may only be required at low velocities.

Similarly, in the statically stable cases, forward-swept blade loads serve to counteract unstable aft blade loads. At the most forward c.g. location, the modeshapes involve large aft blade bending amplitude relative to forward blade bending amplitude. These configurations demonstrate the lowest flutter dynamic pressures. As c.g. moves aft, there is an increase in the relative forward blade bending amplitudes as well as a decrease in the longitudinal static margin, both of which cause reductions in the vehicle pitch moment. In addition, the body-freedom flutter dynamic pressures improve. Thus, the same decrease in vehicle pitch moment which encourages vehicle divergence discourages body-treedom flutter.

This statement is supported by aeroelastic tailoring results. When aft blades experience cross-coupting induced washout, an overall decrease in pitch moment occurs. Figure 10 emphasizes the associated increase in flutter dynamic pressure.

It is noted that the tendency to have an increasing body-freedom flutter dynamic pressure with a decreasing longitudinal static stability margin has been shown in two previous studies. One study involved tlutter of the X-29 [3] and the other involved tlutter of a tailless sailplane [15]. As another point of interest, the addition of a tail would probably increase nose down pitching moment and therefore would shift the dynamic divergence curve to the right as shown in Figure 11 . The flutter boundary, however, would drop because increases in pitch moment have been shown to be destabilizing.

\section{Conclusions}

The X-Wing's typical aeroelastic instability while in the fixed-rotor mode is body-freedom flutter, a low frequency interaction between the first elastic mode and the short period mode. Over c.g. variations, parametric cases with the negative static margins demonstrated the highest flutter dynamic pressures. As the ratio of $\mathrm{X}$-Wing rotorto-fuselage mass increased, the flutter boundary decreased. This trend is due to a drop in first elastic mode natural frequency with increasing mass ratio. The decrease in flutter dynamic pressures was emphasized as c.g. location moved forward. An increase in forward-swept blade bending amplitude relative to aft-swept blade bending amplitude in the first elastic mode due to sweep angle variations had a stabilizing effect on the flutter boundaries at two different c.g. locations. Finally, negative stiffness cross-coupling or washout when incorporated into the ant blades caused the flutter dynamic pressure to increase above the 'uncoupled' flutter dynamic pressure. Positive cross-coupling in the aft blade or washin was destabilizing. In the lorward-swept blades, stiffness cross- 
coupling had little effect on stability for the parametric case evaluated. Finally, it was concluded that in most cases forward blade loads and aft blade loads tended to counteract each other in the presence of body treedoms.

\section{Apoendix}

Substituting the acrodynamic approximation, Eqn.3, into Eq̣n. 1 yields

$[\hat{\mathrm{M}}]_{\mathrm{s}^{2}}^{2}+[\hat{\mathrm{C}}] \mathrm{s}+[\hat{\mathrm{K}}]+$

$$
\left.\sum_{i=1}^{L}\left[W_{i}\right] s\right]\{\eta(s)\}=0
$$

where

$$
\begin{aligned}
& {[\hat{M}]=\left[M^{\prime}\right]+q\left[A_{2}\right]\left(\frac{b}{V}\right)^{2}} \\
& {[\hat{C}]=\left[C^{\prime}\right]+q\left[A_{1}\right] \frac{b}{V}} \\
& {[\hat{K}]=\left[K^{\prime}\right]+q\left[A_{0}\right]}
\end{aligned}
$$

and where

$$
\left[w_{i}\right]=\frac{q\left[B_{i}\right]}{s+\frac{V \beta_{i}}{b}}
$$

First order state equations for the aerodynamic approximation terms can be obtained as

$$
y_{i}=\frac{q s\left[B_{i}\right]^{\eta}}{s+\frac{v \beta_{i}}{b}}=s\left[w_{i}\right] \eta
$$

or

$$
\left(s+\frac{V \beta_{i}}{b}\right) y_{i}=q s\left[B_{i}\right] \eta
$$

which implies

$$
s y_{i}=-\frac{v \beta_{i}}{b} I y_{i}+q s\left[B_{i}\right] \eta
$$

which is a first order differential equation in $y_{i}$ with I as the identity matrix.

A state vector $z$ is detined for the system in which each derodynamic lag contributes a state,

$$
z^{T}=\left\{\begin{array}{lll}
\eta^{T} & s \eta^{T} & y_{1}^{T} \ldots . . . y_{L}^{T}
\end{array}\right\}
$$

Thus, a state space representation of the system can be written by combining equations $A-3$ and $A-4$,

$$
s z=[F] z
$$

where

$F !=$

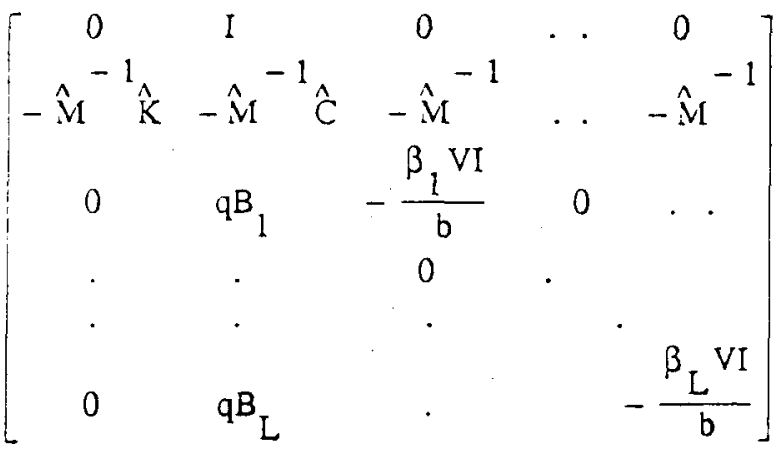

In the time domain, the state space form is

$$
\dot{\mathrm{z}}=[F] \mathrm{z}
$$

\section{References}

1. Williams, R. M., "X-Wing and the Navy VSTOL Initiative," AIA Student Journal, Vol. 19, No. 4, Winter 1981-82, pp.26-34.

2. Cheeseman, I.C. and Seed, A.R., "The Application of Circulation Control Blowing to Helicoptor Rotors," Joumal of Reval Aeronautical Sociery, Vol. 71 , No.348, July 1966.

3. Weisshaar, T.A., Zeiler, T. A., Herz, T. J., and Shirk, M. H., "Flutter of Forward Swept Wings, Analyses and Tests," Structures, Structural Dynamics and Materials Conference, May 1982, NAA Paper No. $32-0646$.

4. Gimmestad, D. W., "A Preliminary Divergence and Flutter Evaluation of an X-Wing Aircraft," ALA Aircraft Systems and Technology Conierence, AIAA Paper No. 81-1671, Aug. 1981.

5. Gilbert, M. G., and Silva, W. A., "The Effects of Aeroelastic Deformation on the Unaugmented Stopped-Rotor Dynamics of an X-Wing Aircraft," Atmospheric Flight Mechanics Conference, Aug. 1987. AIAA Paper No. 87-2563CP.

6. Haas, D. and Chopra, I., "Flutter of Circulation Control Wings," AIAA ASME/ ASCE/AHS 29th Structures, Structural Dynamics and Materials Conference, Williamsburg, VA, April 19-20, 1988.

7. Geising.J.P., Kalman, T.P. and Rodden, W.P., "Subsonic Unsteady Aerodynamics for General Conligurations, Part I: Direct Application of the Nonplanar Doublet Lattice Method,"

AFFDL-TR-715, 1971. 
8. Mukhopadhyay, V., Newsom, J.R. and Abel, I., "A Method for Obtaining Reduced Order Control Laws for High Order Systems Using Optimization Techniques," NASA TP-1876, Aug. 1981.

9. Engineering Analvsis Language Engineering Iniormation Systems, Inc., San Jose, CA. 1983.

10. Foist, B.L., "Aeroelastic Stability of Aircraft with Advanced Composite Wings," M.S. Thesis, School of Aeronautics and Astronautics. Purdue University, W. Lafayette, IN, Aug. 1982.

11. Weisshaar. T.A., "Flutter and Divergence of Airfoils ross-coupling," Purdue University, AAE-84-15.

12. ams, W.M., "A Digital Program of Interaction Between Flexible eady Aerodynamics and Active iA TM-80040, 1979. sion with Walter A. Silva, Dec. 1988.

14 15 'Flutter Characteristics of High Aspect tircraft," Engineering Notes, Journal 1.21, No. 9. Dec. 1984.

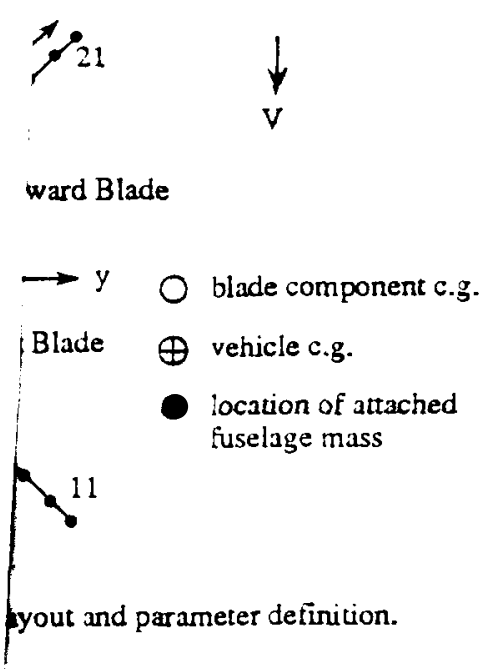

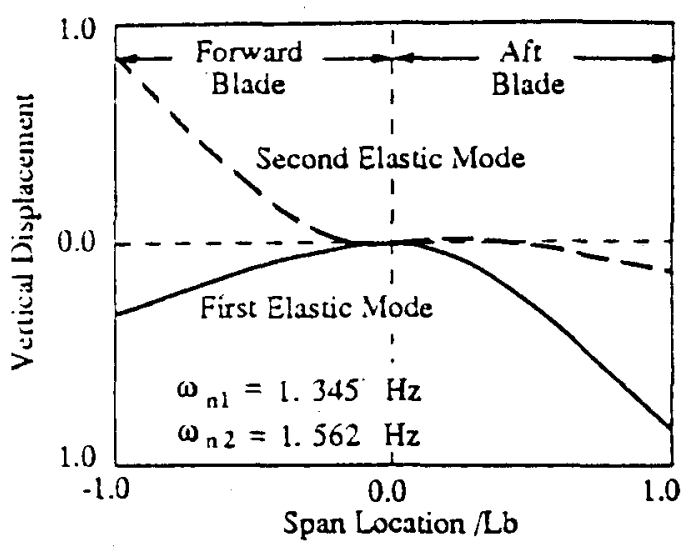

Fig. 2 Modeshapes and frequencies for nominal case.

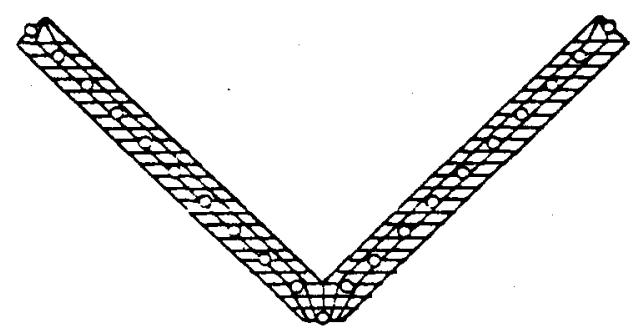

Fig. 3 Typical panel layout showing structural node locations.

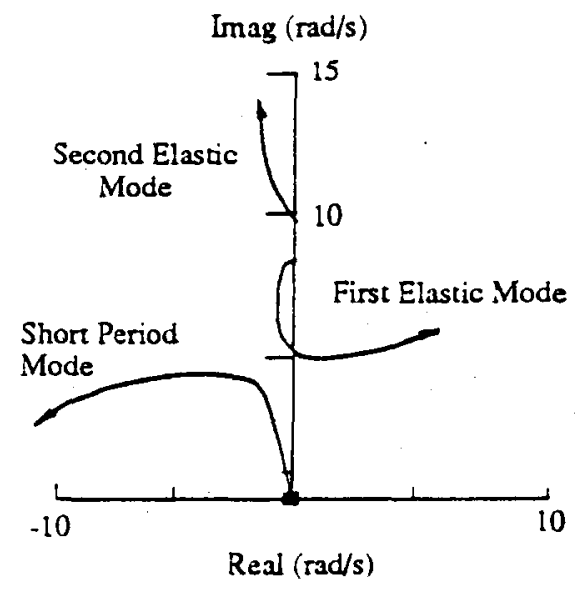

Fig. 4 Root locus for nominal case. 


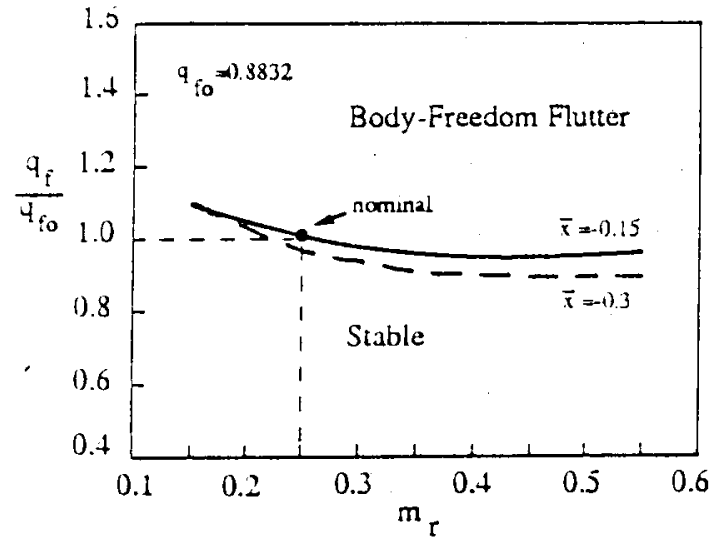

Fig. 5 Flutter dynamic pressure as a function of $m_{r}$ and $\bar{x}$.

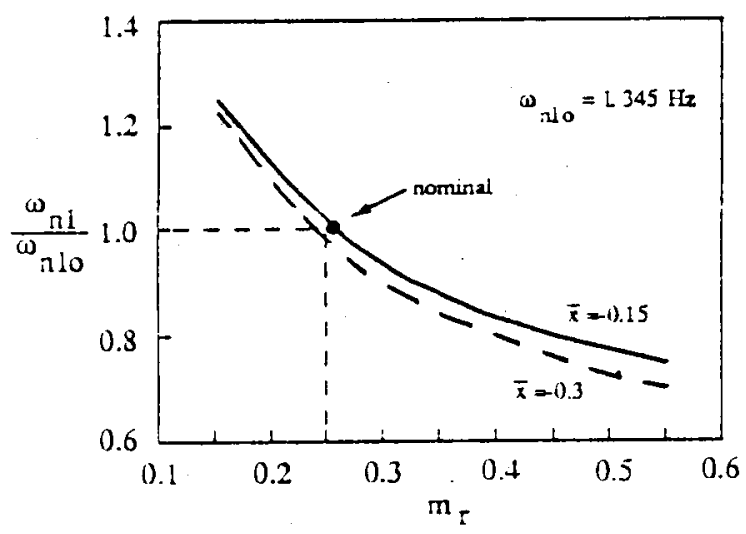

Fig. 6 Variation of narural frequency with $\bar{x}$ and $m_{r}$

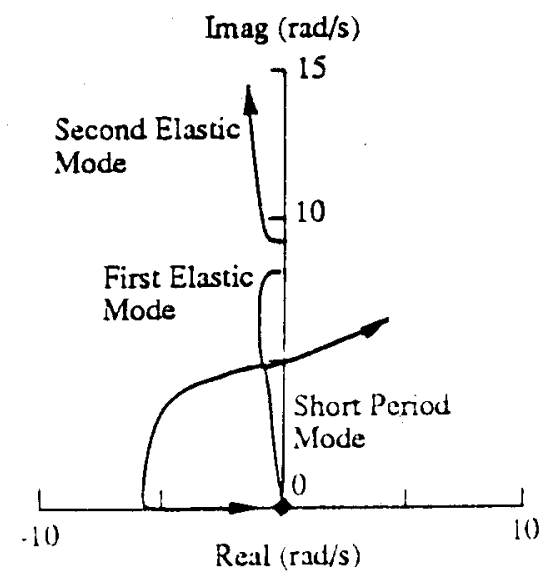

Fig. ? Root locus of $\Lambda=30^{\circ}, \bar{x}=-0.3$ conriguration illustrating interaction of short period and tirst elastic modes.

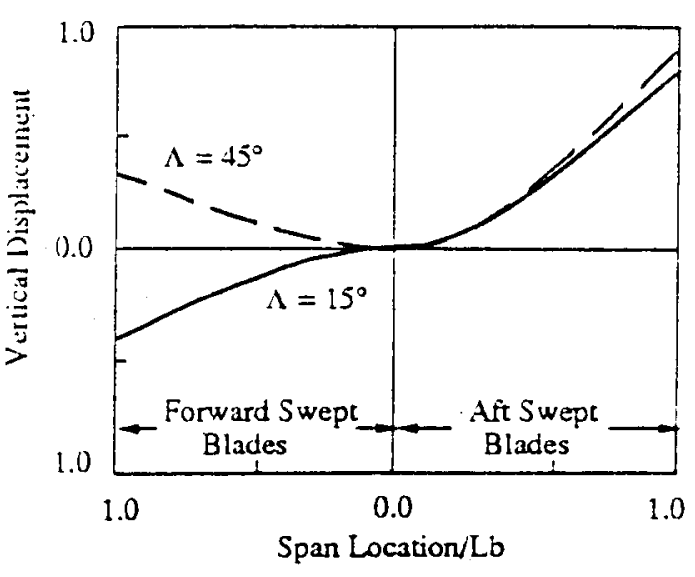

Fig. 8 Variation of first elastic mode as $\Lambda$ increases for configurations with $\bar{x}=-0.15$.

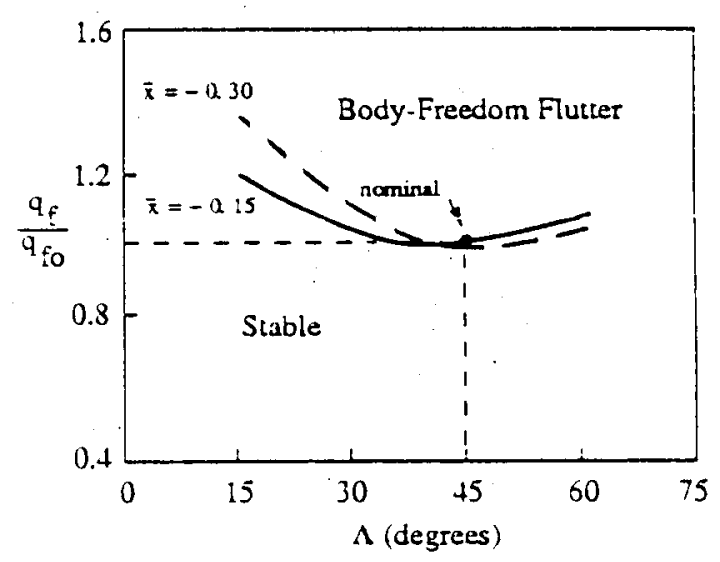

Fig. 9 Variation of flutter boundary with changes in sweep angle.

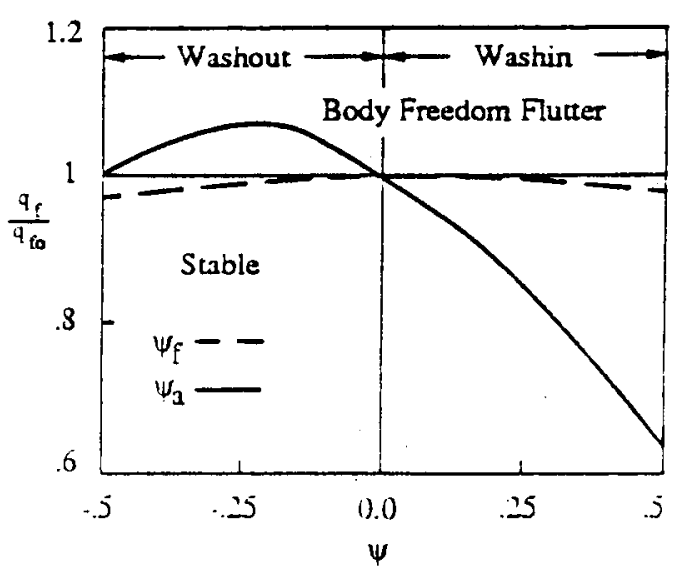

Fig. 10 Variation of llutter dymamic pressure with $\psi$ as it is applied independendy to the forward-swept blade $\left(\psi_{f}\right)$ and to the aftswept blade $\left(\psi_{3}\right)$. 


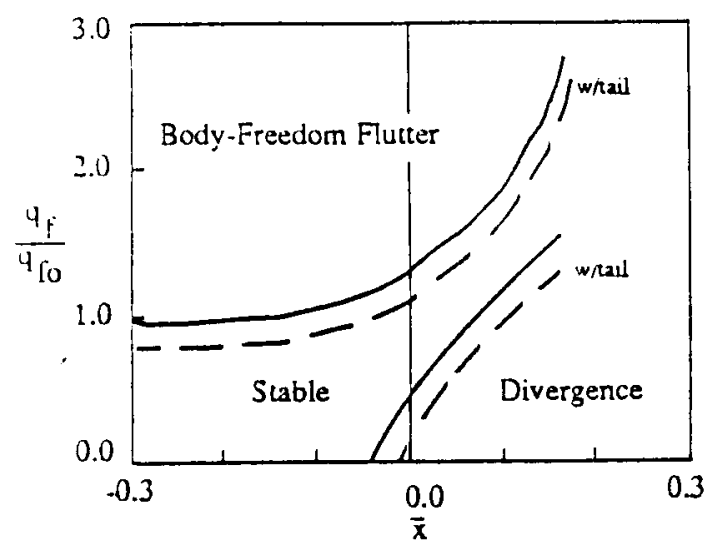

Fig. 11 Stability boundaries as function of $\bar{x}$, including the effect of a tail.

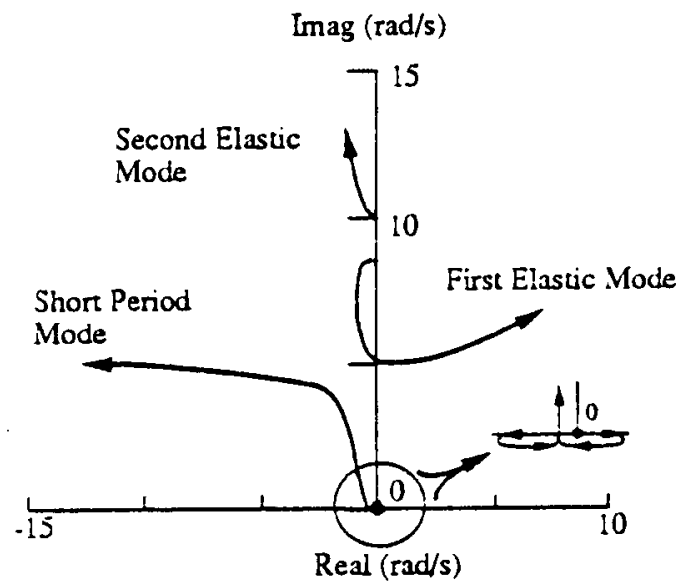

Fig. 12 Root locus illustrating restabilization of the short period mode roots along the real axis.

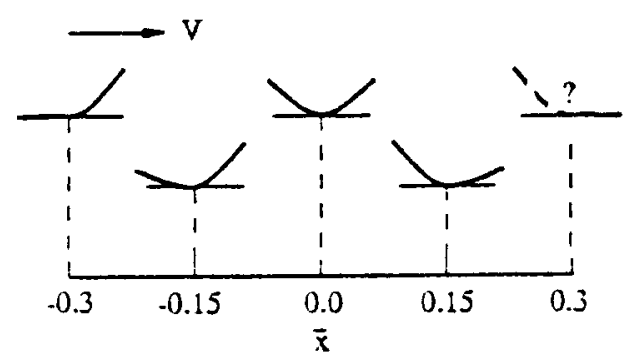

Fig. 13 Transition of first elastic mode vertical displacement as a function of $\vec{x}$. 


\begin{tabular}{l} 
NASA TM-101572 \\
Report No \\
Results of a Parametric Aeroelastic Stability \\
Analysis of a Generic X-Wing Aircraft \\
/ Authoris \\
Jessica A. Woods \\
Michael G. Gilbert \\
Terrence A. Weisshaar \\
9. Performing Organization Name and Address \\
NASA Langley Research Center \\
Hampton, VA 23665-5225 \\
\hline 12. Sponsoring Agency Name and Address
\end{tabular}

National Aeronautics and Space Administration Washington, DC 20546-0001
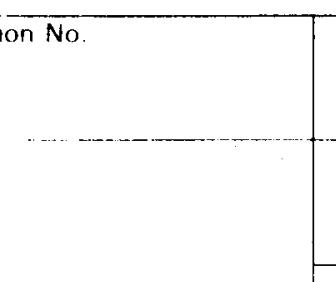

5. Report Date

April 1989

6. Performing Organization Code

8. Performing Organization Report No

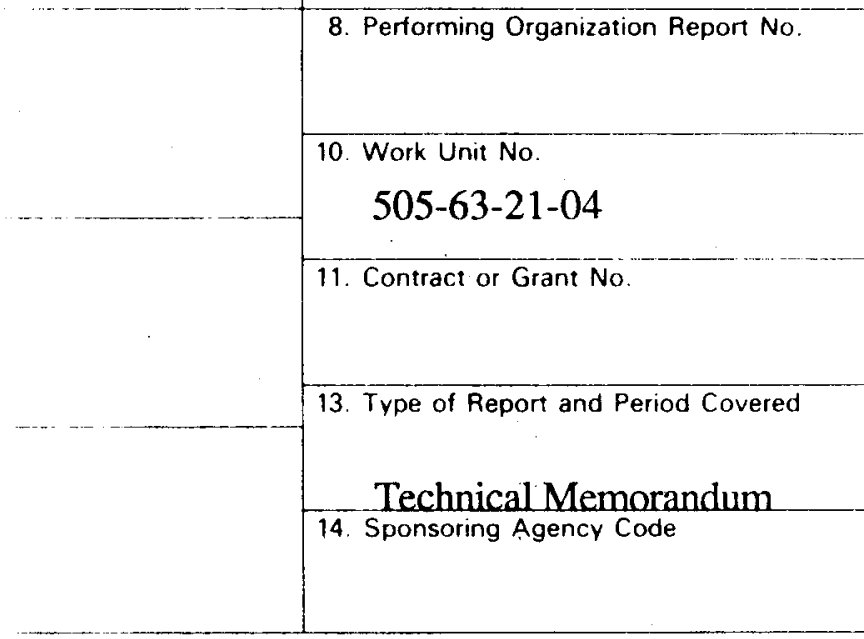

15. Supplementary Notes

Presented at the AIAA 30th Structures, Structural Dynamics and Materials Conference in Mobile, Alabama, April 3-5, 1989.

16. Abstract

This paper discusses the trends in longitudinal dynamic aeroelastic stability of a generic X-Wing aircraft model with design parameter variations. X-Wing rotor blade sweep angle, ratio of blade mass to total vehicle mass, blade structural stiffness cross-coupling and vehicle center-of-gravity location were parameters considered. The typical instability encountered is body-freedom flutter involving a low frequency interaction of the first elastic mode and the aircraft short period mode. Parametric cases with the lowest static margin consistently demonstrated the highest flutter dynamic pressures. As mass ratio was increased, the flutter boundary decreased. The decrease was emphasized as center-of-gravity location was moved forward. As sweep angle varied, it was observed that the resulting increase in forward-swept blade bending amplitude relative to aft blade bending amplitude in the first elastic mode had a stabilizing effect on the flutter boundary. Finally, small amounts of stiffness cross-coupling in the aft blades increased flutter dynamic pressure.

$17 \mathrm{Ker}$ Words (Suggested by Author(s)

$X$-Wing Aircraft

Body-Freedom Flutter

Aeroelastic Tailoring

Aeroelasticity

Parametric Variations

19. Security Classif. (of this report)

Unclassified
18 Distribution Statement

Unclassified - Unlimited

Subject Category - 39
20. - -...unity Classif. (of this page)

Unclassified
21. No of pages

10
22. Price

$\mathrm{A} 02$ 